\title{
Lymphocytic infiltration of the brain in sleeping sickness
}

\author{
B M GREENWOOD, H C WHITTLE, K O ODULOJU, R R DOURMASHKIN
}

British Medical fournal, 1976, 2, 1291-1292

suspended in medium 199 supplemented by $10 \%$ fetal calf serum and kept at $4{ }^{\circ} \mathrm{C}$. Later McCoy's medium containing $0.5 \%$ fetal calf serum was used and cells were kept at room temperature. Viabilities, assessed by trypan-blue exclusion, were better when McCoy's medium was

\section{Summary}

Cerebrospinal fluid mononuclear cells from 40 patients with advanced Gambian sleeping sickness were examined for intracytoplasmic immunoglobulin and for B- and T-lymphocyte markers. About $5 \%$ of mononuclear cells were plasma cells. Most of the lymphocytes present were $B$ cells. These findings suggest that the considerable lymphocytic infiltration of the nervous system seen in advanced sleeping sickness is not a cell-mediated immune reaction to trypanosomes. Immune complexes may play a part in producing the brain damage characteristic of this disease.

\section{Introduction}

The brains of patients with advanced Gambian sleeping sickness show characteristic changes. ${ }^{1}$ The meninges are thickened and infiltrated with lymphocytes, plasma cells, and morular cells. Extension of this cellular infiltrate into the perivascular spaces produces prominent perivascular cuffing. Vascular damage occurs and the brain substance may be infiltrated with mononuclear cells. How trypanosomes produce these changes is not known.

Lymphocytic infiltration of the brain and meninges is a prominent feature of many forms of viral encephalitis such as lymphocytic choriomeningitis. In these infections the infiltrating lymphocytes are thought to be $\mathrm{T}$ lymphocytes involved in a strong cell-mediated immune reaction to the virus. Lymphocytic infiltration of the nervous system in sleeping sickness might also result from a cell-mediated immune reaction to the causative organism. If this were the case most of the infiltrating lymphocytes would be $\mathrm{T}$ lymphocytes. We studied this possibility indirectly by looking at the nature of the mononuclear cells present in the cerebrospinal fluid (CSF) of patients with advanced Gambian sleeping sickness.

\section{Patients and methods}

Forty patients with advanced Trypanosoma gambiense infection were studied. Diagnosis was made by detecting either trypanosomes in CSF or a high CSF IgM in a patient with clinical features suggesting sleeping sickness. All patients were studied before the start of treatment with melarsoprol.

\section{SAMPLES}

Most samples were collected from patients seen at the field station of the Nigerian Institute for Trypanosomiasis Research at Gboko, Nigeria. CSF was centrifuged immediately after collection, the supernatant removed, and the cells suspended in tissue culture medium before being transported by road to Zaria. Cells were examined one to three days after collection. In the early part of the study cells were

Department of Medicine, Ahmadu Bello University, Zaria, Nigeria B M GREENWOOD, MRCP, senior lecturer

H C WHITTLE, MRCP, senior lecturer

K O ODULOJU, FIMLT, superintendent technologist

Clinical Research Centre, Harrow, Middlesex

R R DOURMASHKIN, MD, consultant electronmicroscopist from $33^{\circ},-90^{\circ} \%$ with a mean of $68_{\%}^{\circ}$.

The effects of two days' incubation on B- and T-cell markers were investigated using Ficoll-Hypaque purified peripheral blood lymphocytes. After incubation for 48 hours at room temperature in McCoy's medium there was a small loss in the number of immunoglobulinbearing cells $(20 \%-30 \%)$, but no loss in the number of cells forming rosettes with sheep red cells.

Because only a few CSF leucocytes were obtained from most patients we could carry out only a limited number of investigations on each sample. Investigations were therefore carried out sequentially, beginning with cell morphology studies and immunofluorescence of fixed preparations. Lymphocytes were then tested for B-and T-cell markers and for their ability to respond to plant mitogens. Finally two cell preparations were examined by electron microscopy.

\section{LABORATORY METHODS}

Cytocentrifuge preparations of CSF mononuclear cells were fixed in cold acetone and stained for intracytoplasmic immunoglobulin with anti-whole immunoglobulin and anti-IgM conjugates (Burroughs Wellcome).

$\mathrm{T}$ lymphocytes were identified by the sheep red cell rosetting test. ${ }^{2}$ $100 \mu \mathrm{l}$ of lymphocyte suspension was added to $100 \mu \mathrm{l}$ of $1 \%$ washed sheep red cells and $50 \mu \mathrm{l}$ of fetal calf serum previously absorbed with sheep erythrocytes. The mixture was incubated for five minutes at $37^{\circ} \mathrm{C}$, centrifuged at $100 \mathrm{~g}$ for five minutes, and stored overnight in crushed ice. Cells binding three or more red cells were counted. B lymphocytes were identified by the presence of immunoglobulin on their surface when stained with an anti-whole immunoglobulin conjugate. When enough lymphocytes were available class-specific conjugates were also used. Conjugates were absorbed with liver powder, millipored, and ultracentrifuged before being stored in small aliquots.

CSF lymphocytes were cultured for three days in U microtitre trays. Cells were suspended at a concentration of $1 \times 16^{6}$ lymphocytes $/ \mathrm{ml}$ in RPMI 1640 medium buffered with HEPES and bicarbonate and supplemented with $10 \%$ fetal calf serum. Phytohaemagglutinin (PHA) was used at a final concentration of $50 \mathrm{mg} / \mathrm{l}$ and pokeweed mitogen (PWM) (Grand Island Biological Company) at a final concentration of $1 / 100 .^{3} \mathrm{H}$-Thymidine was added after 48 hours of culture, and cells were harvested 18 hours later. A stimulation ratio was calculated:

(counts per minute - background in stimulated culture) $\div$ (counts per minute - background in control culture).

Cells for electron microscopy were fixed in a paraformaldehydeglutaraldehyde mixture, ${ }^{3}$ washed three times in $0 \cdot 1-M$ cacodylate buffer, $\mathrm{PH} 7 \cdot 2$, containing $5 \%$ sucrose, and sent to England. They were subsequently collected in an agar pellet, fixed in $1 \%$ osmium tetroxide buffered with $0 \cdot 1-\mathrm{M}$ cacodylate buffer, $\mathrm{PH} 7 \cdot 2$, dehydrated, and embedded in Spurr resin. ${ }^{4}$ Sections were cut with a diamond knife, stained with uranylacetate and lead citrate, and examined in a Philips EM 300.

\section{Results}

Cell morphology-Cytocentrifuge preparations of CSF from eight patients with advanced sleeping sickness, stained with May-Grünwald stain, were examined. In each sample more than $90 \%$ of the cells present were lymphocytes or lymphoblasts (mean $94 \%$ ). About $70 \%$ were small lymphocytes, but large lymphoblastic cells with prominent cytoplasm were also present. A few plasma cells were seen in five of the eight samples. Occasional morular cells packed with vesicles were seen in four samples. Polymorphoneutrophil leucocytes were not seen, but occasional eosinophils were present. 
Intracytoplasmic immunoglobulin-Cytocentrifuge preparations of CSF from 15 patients were examined for intracytoplasmic immunoglobulin by immunofluorescence. A mean of $4.5 \%$ of cells stained with an anti-whole immunoglobulin conjugate (range 1\%-10\%) and a mean of $4.6 \%$ (range $1 \%-11 \%$ ) with an anti-IgM conjugate. Occasional bright staining morular cells were seen.

$T$ - and B-lymphocyte markers-Lymphocytes from the CSF of 13 patients were examined for T- and B-cell markers. Immunoglobulinbearing lymphocytes predominated (see table). Surface IgM was detected more often than IgG, in contrast to the findings in normal peripheral blood lymphocytes, where IgG predominated. No correlation was found between CSF IgM levels and B-cell percentage.

Lymphocyte subpopulations in CSF of 13 patients with advanced Gambian sleeping sickness and in peripheral blood of 16 heathly adult Nigerians. Results are means and ranges

\begin{tabular}{c|c|c|c|c|c}
\hline & $\begin{array}{c}\text { E-rosetting } \\
\text { cells } \\
(\%)\end{array}$ & $\begin{array}{c}\text { Whole Ig } \\
(\%)\end{array}$ & $\begin{array}{c}\text { IgA } \\
(\%)\end{array}$ & $\begin{array}{c}\text { IgG } \\
(\%)\end{array}$ & $\begin{array}{c}\text { IgM } \\
(\%)\end{array}$ \\
\hline $\begin{array}{c}\text { CSF lymphocytes in } \\
\text { patients with try- }\end{array}$ & $11(3-31)$ & $61(36-76)$ & $4(0-10)^{*}$ & $26(17-36) *$ & $32(12-44) *$ \\
panosomiasis \\
Bood lymphocytes in \\
controls ..
\end{tabular}

*Values from five patients.

Lymphocyte stimulation by $P H A$ and $P W M-C S F$ lymphocytes from five patients were cultured in the presence of PHA and PWM. The mean stimulation ratios obtained were similar $-4 \cdot 1$ for PHA and 4.2 for PWM. In contrast, peripheral blood lymphocytes from 10 healthy adults gave a much higher mean stimulation ratio with PHA (33.9) than with PWM (10.6).

Electron microscopy-Mononuclear cells from two CSF samples were examined by electron microscopy. One sample came from a patient with a high CSF white cell count; the other was a pool obtained from three patients. In both specimens most cells were small lymphocytes. About $5 \%$ of the cells in each preparation, however, showed many layers of rough endoplasmic reticulum in their cytoplasm and had an eccentric nucleus with marginated chromatin. These cells thus had the characteristics of plasma cells. In addition, a few cells of lymphoid origin were seen which contained large amorphous cytoplasmic inclusions. These were probably morular cells (see figure).

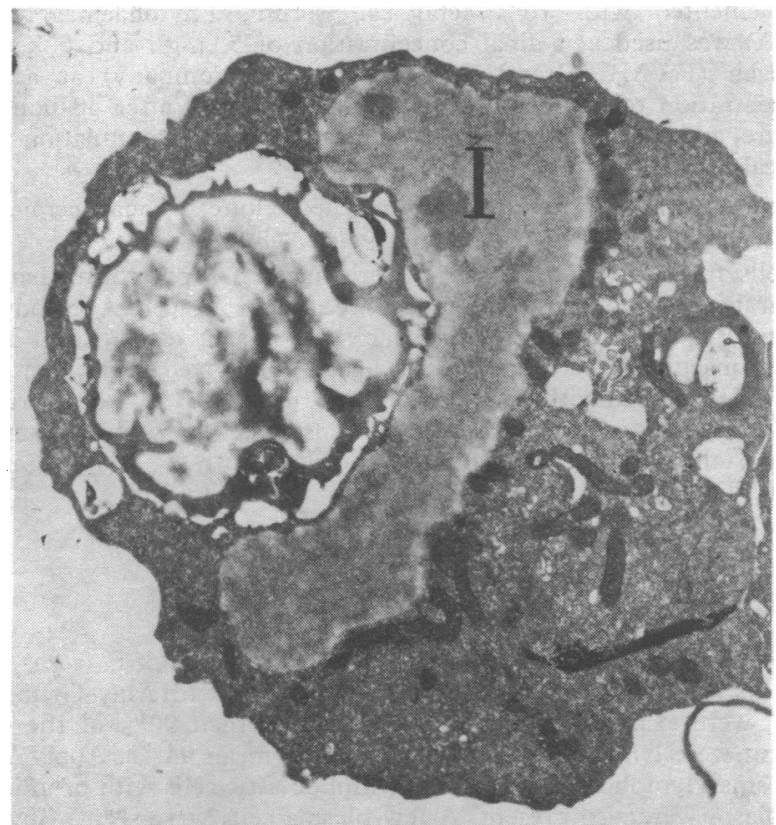

Electron micrograph of a mononuclear cell in the CSF of patient with advanced sleeping sickness showing one large intracytoplasmic inclusion (I), probably of IgM. $(\times 11625$.

\section{Discussion}

We have shown that about $5 \%$ of the mononuclear cells present in the CSF of patients with advanced sleeping sickness were plasma cells. A similar figure was obtained by immunofluorescence and by electron microscopy. The remaining cells were lymphocytes or lymphoblasts. Most of these cells stained for surface immunoglobulin and were therefore probably B cells. IgM is present in large amounts in the CSF of many patients with advanced sleeping sickness. Passive absorption of this immunoglobulin on to CSF lymphocytes might have accounted for the high proportion of immunoglobulin-staining cells found in our patients. We think that this is unlikely as B-cell counts remained high after two or three days of incubation in tissue culture medium and because no correlation was found between CSF B-cell counts and CSF IgM levels. Furthermore, CSF lymphocytes responded as well to PWM as to PHA, which suggested that many B cells were present. Therefore B lymphocytes probably predominate in the CSF of patients with advanced sleeping sickness.

In advanced sleeping sickness lymphocytic infiltration occurs predominantly in the meninges and in the perivascular cuffs of the brain. As the perivascular spaces are in direct contact with the main subarachnoid space, we think it likely that the lymphocytes present in the lumbar CSF are representative of those infiltrating the meninges and the brain. If this assumption is correct it is unlikely that a delayed hypersensitivity reaction to trypanosomes or their products plays an important part in the pathogenesis of sleeping sickness, as few $T$ lymphocytes were found. Tissue damage might result from local formation of immune complexes, as immunoglobulin and antibody are formed within the nervous system in patients with this infection. ${ }^{5}$ The occurence of low serum C3 levels in patients with advanced sleeping sickness, when trypanosomes are largely restricted to the nervous system, provides some support for this view. ${ }^{6}$ In the presence of antibody trypanosomes can be damaged by $\mathrm{K}$ cells. $\mathrm{K}$-cell killing of trypanosomes in the brain, with the consequent release of toxic products, is another possible mechanism of tissue damage in this disease.

The few lymphocytes present in normal CSF are mainly $T$ cells, ${ }^{8-10}$ but little is known about the nature of the lymphocytes present in the CSF of patients with infections of the nervous system. All CSF lymphocytes were found to be rosetting cells in a patient with tuberculous meningitis, ${ }^{11}$ a condition that is sometimes difficult to differentiate clinically from sleeping sickness. Variable results have been obtained in the few patients with viral meningitis who have been studied.1011

More extensive studies are needed to show whether characterising CSF lymphocytes can be of clinical help in the diagnosis and management of patients with infections of the nervous system.

We thank Dr A A Amodu for allowing us to study patients at Gboko; Dr B Aiyedun and the staff of the Nigerian Institute for Trypanosomiasis Research for their help; Professor G M Edington for his help with interpreting histological sections; and $\mathrm{Mr} \mathrm{D}$ Shah for his help with the electron microscopy. This study was supported by the Medical Research Council.

\section{References}

1 Mott, F W, Reports of the Sleeping Sickness Commission of the Royal Society, 1906, 7, 3

2 Jondal, M, Holm, G, and Wigzell, H, fournal of Experimental Medicine, 1972, 136, 207.

3 Karnovsky, M J, Fournal of Cellular Biology, 1965, 27, 137A.

4 Spurr, A R, Fournal of Ultrastructure Research, 1969, 26, 31

5 Greenwood, B M, and Whittle, H C, Lancet, 1973, 2, 525.

- Greenwood, B M, and Whittle, H C, Clinical and Experimental Immunology, 1976, 24, 133

7 Mkwananzi, J B, Franks, D, and Baker, J R, Nature, 1976, 259, 403

8 Manconi, P E, et al, New England fournal of Medicine, 1976, 294, 49.

- Gangii, D, et al, New England fournal of Medicine, 1976, 294, 902.

10 Naess, A, Scandinavian fournal of Immunology, 1976, 5, 165.

11 Goasguen, J, and Sabouraud, O, Nouvelle Presse Médicale, 1974, 3, 2266.

$$
\frac{100}{20}
$$

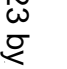

